\title{
Production of Monohydroxy Derivatives from Highly Unsaturated Fatty Acids in the Gills of Red Sea Bream Pagrus major
}

\author{
Noriaki Iijima, Takahiko Hada ${ }^{\dagger}$ and Mitsu Kayama ${ }^{\dagger \dagger}$ \\ Faculty of Applied Biological Science, Hiroshima University, Higashi-Hiroshima, Hiroshima 739, Japan \\ (Received May 10, 1995)
}

\begin{abstract}
12-Hydroxyeicosatetraenoic acid and 15-hydroxyeicosatetraenoic acid were produced as major and minor monohydroxylated products in a microsome fraction, when $\left[1-{ }^{14} \mathrm{C}\right]$ arachidonic acid was incubated with the microsome or cytosol fraction prepared from frozen stored gill tissue of red sea bream Pagrus major. The endogeneous products extracted from the microsome fraction of red sea bream gill were isolated by high performance liquid chromatography and identified as 12-hydroxyeicosatetraenoic acid, 12-hydroxyeicosapentaenoic acid and 14-hydroxydocosahexaenoic acid by ultraviolet absorption spectrometry and gas chromatography-mass spectrometry. These data suggest that arachidonic acid, eicosapentaenoic acid and docosahexaenoic acid are converted to their monohydroxy derivatives via the hydroperoxides by the action of 12-lipoxygenase-like enzyme, which is distributed in the microsomes of red sea bream gill.
\end{abstract}

Key words: red sea bream, gill, 12-hydroxyeicosatetraenoic acid, 12-hydroxyeicosapentaenoic acid, 14-hydroxydocosahexaenoic acid, highly unsaturated fatty acid, GC-MS

The hydroxyeicosatetraenoic acids (HETEs) are products of arachidonic acid (AA)(n-6) metabolism that are derived primarily from the lipoxygenase pathways. Recently, it has been shown that HETEs play more important biological roles than was considered previously. ${ }^{\text {) }}$ However, only limited information is available on the enzymatic oxygenated products of n-3 highly unsaturated fatty acids.

The n-3 polyunsaturated fatty acids, mostly eicosapentaenoic acid (EPA)(n-3) and docosahexaenoic acid (DHA) $(n-3)$, are the major fatty acid components in fish tissues, in particular marine fish.,3) German et al. ${ }^{4-10)}$ showed that AA (n-6), EPA (n-3) and DHA (n-3) are converted to their oxygenated derivatives by the action of lipoxygenase in the gills and skin of the freshwater fish, rainbow trout. They further investigated the properties of the lipoxygenases in the gills and skin of rainbow trout and other fishes. ${ }^{11-13)}$ In addition, it was estimated that 12-hydroxyeicosatetraenoic acid (12-HETE) and 12-hydroxyeicosapentaenoic acid (12HEPE) were also yielded enzymatically in the skins of wild and cultured ayu. ${ }^{14)}$ Leukotrienes were also synthesized in the blood cells of rainbow trout ${ }^{15,16)}$ and the eel gill. ${ }^{17)}$

In general, marine fish require $\mathrm{n}-3$ series highly unsaturated fatty acids such as EPA and DHA, rather than the n6 series, for growth. ${ }^{2)}$ Therefore, it is neccesary to investigate the conversion of the n-3 polyunsaturated fatty acids through enzymatic oxygenation in the tissues of marine fish. Tocher and Sargent ${ }^{18)}$ clarified that leukotrienes are produced in the neutrophiles of the marine fish, plaice. However, there is a paucity of information on the lipoxygenase products in the tissues of marine fishes.

Kayama and his collaborators ${ }^{19-21)}$ have studied the prostaglandin syntheses and aggregation behavior in carp, rainbow trout, and red sea bream thrombocytes in comparison to those in human platelets. Recently, they dealt with the prostagladin syntheses from exogeneous AA, EPA and DHA in washed thrombocyte suspensions of four species of marine fish; black sea bream, black rock fish, plaice and red sea bream. ${ }^{22)}$ In this paper, the authors report the identification of monohydroxylated metabolites of gill tissue in red sea bream, Pagrus major, which was examined with high performance liquid chromatography (HPLC), ultraviolet spectrophotometry, and gas chromatography-mass spectrometry (GC-MS).

\section{Materials and Methods}

\section{Reagent}

$\left[1{ }^{14} \mathrm{C}\right]$ Arachidonic acid $\left(2 \times 10^{6} \mathrm{kBq} / \mathrm{mmol}\right)$ was obtained from New England Nuclear through Nippon Isotope Association. Arachidonic acid (AA) was purchased from Nacalai Tesque. 5-HETE, 8-HETE, 9-HETE, 11HETE, and 15-HETE were kindly provided by Professor Dr. S. Yamamoto, Department of Biochemistry, Tokushima University. 12-HETE was purchased from Sigma Chemical Co. $p$-Toluenesulfonyl- $N$-methyl- $N$-nitrosoamide, trimethylchlchlosilane, $N$-(trimethylsilyl)imidazole, imidazole, tert-butyldimethyl chlorosilane and $N, O$-bis (trimethylsilyl)trifluoroacetoamide were purchased from Nacalai Tesque. Dimethylformamide was obtained from Pierce Chemical Co., platinum oxide from Wako Pure Chemical Industries, Ltd. Silicic acid (100 mesh) for column chromatography was purchased from Mallinckrodt Inc. and precoated Silica Gel 60 glass plates from E. Merck.

\footnotetext{
$\uparrow^{\dagger}$ Present address: Institute for BioMedical Research, Teijin Pharmaceutical Ltd., Asahigaoka, Hino, Tokyo 191, Japan.

\# Present address: Faculty of Engineering, Fukuyama University, Gakuen-cho, Fukuyama, Hiroshima 729-02, Japan.
} 


\section{Preparation of Microsome and Cytosol Fractions}

Gills of freshly killed red sea bream (body weight, 1-2 $\mathrm{kg}$ ) were rinsed in ice-cold $0.85 \% \mathrm{NaCl}$ to remove adhering blood, and then stored at $-40^{\circ} \mathrm{C}$ for 1 to 3 months.

All the following procedures were performed at $0-4^{\circ} \mathrm{C}$. After thawing, gill filaments were cut from the gill arches and homogenized by a Polytron homogenizer in 3 volumes of $50 \mathrm{~mm}$ Tris- $\mathrm{HCl}$ (pH 7.5) containing $1 \mathrm{~mm}$ reduced glutathione (GSH). Tissue homogenate was centrifuged at $6,000 \times g$ for $10 \mathrm{~min}$, and the resulting supernatant was further ultracentrifuged at $100,000 \times g$ for $60 \mathrm{~min}$. The cytosol fraction (supernatant) was collected, and the microsome fraction (precipitates) was suspended in $50 \mathrm{~mm}$ Tris$\mathrm{HCl}(\mathrm{pH} \mathrm{7.5)}$ containing $1 \mathrm{~mm} \mathrm{GSH}$ at an equal volume of cytosol fraction. The microsome and cytosol fractions were used as crude enzyme solutions.

\section{Enzyme Reactions with $A A$}

Five $\mu l$ of $\left[1{ }^{14} \mathrm{C}\right] \mathrm{AA}$ in ethanol $(8.3 \mathrm{kBq})$ was added in $295 \mu l$ of microsome and cytosol fractions, respectively, at a final concentration of $2.5 \mu \mathrm{M}$. The reaction was initiated at $17^{\circ} \mathrm{C}$ for $30 \mathrm{~min}$, and stopped by adding $0.4 \mathrm{~m} /$ of a solvent mixture of diethyl ether/methanol $/ 1 \mathrm{M}$ citric acid $(30: 4: 1, v / v / v)$, which was kept at $-20^{\circ} \mathrm{C}$. This was mixed for $15 \mathrm{~s}$ and centrifuged at $1,700 \times g$ for $5 \mathrm{~min}$ at $4^{\circ} \mathrm{C}$. The organic phase was used for thin-layer chromatography (TLC) and HPLC.

\section{$T L C$}

An aliquot of the organic phase was directly spotted on a precoated silica gel glass plate at $4^{\circ} \mathrm{C}$. The plate was developed in a solvent system of petroleum ether $\left(30-60^{\circ} \mathrm{C}\right.$, b.p.)/diethyl ether/acetic acid (15:85:0.1, v/v/v) for $1 \mathrm{~h}$ at $-20^{\circ} \mathrm{C}$. The radioactivities were scanned with an imaging scanner system 400 (Packard).

\section{Silicic Acid Column Chromatography and HPLC}

The organic phase obtained from the reaction mixture of $\left[1-{ }^{14} \mathrm{C}\right] \mathrm{AA}$ and the microsome fraction was evaporated under $\mathrm{N}_{2}$ gas flow. The dry residue was then dissolved in a mixture of petroleum ether $\left(30-60^{\circ} \mathrm{C}, \mathrm{b} . \mathrm{p}\right.$.)/ diethyl ether $(9: 1, v / v)$, and applied to a column packed with silicic acid. The column was first washed with the above solvent mixture, the reaction products then being eluted with petroleum ether $\left(30-60^{\circ} \mathrm{C}\right.$, b.p. $) /$ diethyl ether $(4: 6, v / v)$. The eluted fraction was obtained as the monohydroxy fraction. The fraction was mixed with HETEs standards (each $1 \mathrm{nmol}$ ) and evaporated under reduced pressure. The residue was dissolved in methanol/water $(3: 1, v / v)$ and subjected to HPLC.

HPLC was performed on a TSK-gel ODS-120T column $(4.6 \times 50 \mathrm{~mm}$, Tosoh Co., Ltd.). The column was eluted with a solvent system of methanol/water/acetic acid $(75: 25: 1, \mathrm{v} / \mathrm{v} / \mathrm{v})$ at a flow rate of $1 \mathrm{ml} / \mathrm{min}$. Column effluent was monitored at $235 \mathrm{~nm}$, and each 0.5 and 0.33 $\mathrm{m} l$ of the fraction was collected into a scintillation vial during $0-15$ and $15-25 \mathrm{~min}$, respectively, after injecting the sample into a column. Ten $\mathrm{m} l$ of scintillation cocktail (ACS-II, Amersham) was added to each vial, and the radioactivity was measured by an Aloka liquid scintillation spectrometer (Model LSC-671).

Radioactive peaks I and II (see below) obtained by reverse-phase HPLC were further subjected to straightphase HPLC equipped with a $\mu$ Porasil column (RadialPak, Waters). Elution was carried out with a solvent system of $n$-hexane/iso-propanol/acetic acid (100:1.5:0.1, $\mathrm{v} / \mathrm{v} / \mathrm{v}$ ) at a flow rate of $2 \mathrm{ml} / \mathrm{min}$. Eluate was monitored at the absorbance of $235 \mathrm{~nm}$. Each $2 \mathrm{ml}$ fraction was collected into the scintillation vial and evaporated to dryness. Then $10 \mathrm{~m} l$ of scintillation cocktail (ACS-II, Amersham) was added to each vial, and the radioactivity was counted as described above.

\section{Ultraviolet Absorption Spectrum}

For the preparation of monohydroxylated products, 40 $\mathrm{m} l$ of the solvent mixture of diethyl ether/methanol $/ 1 \mathrm{M}$ citric acid $(30: 40: 1, \mathrm{v} / \mathrm{v} / \mathrm{v})$ was added to $10 \mathrm{~m} /$ of microsome fraction obtained from $16 \mathrm{~g}$ of gill filaments of red sea bream. The mixture was centrifuged at $1,700 \times g$ for $10 \mathrm{~min}$, and the upper ether phase was evaporated under reduced pressure. The residue dissolved in a small volume of petroleum ether/diethyl ether $(9: 1, v / v)$ was applied onto a column of silicic acid, and the monohydroxy fraction was separated as described above. Then the monohydroxy fraction was subjected to reverse-phase HPLC on the columns of Ultrasphere ODS $(4.6 \times 250 \mathrm{~mm}$, Packard) and Ultrasphere ODS $(4.6 \times 50 \mathrm{~mm})$. Peaks 1 and 2 (see below) separated by reverse-phase HPLC were subjected to straight-phase HPLC equipped with a column of Zorbax SIL (4.6 $\times 250 \mathrm{~mm}$, Dupont). Peaks 1, 2-1 and 2-2 (see below) thus obtained were evaporated and dissolved in methanol, and their ultraviolet absorption spectra were recorded on a Shimadzu dual wavelength spectrophotometer (Model UV 3000).

\section{GC-MS}

Samples (peaks 1, 2-1 and 2-2) were esterified with ethereal diazomethane. The aliquots of esterified samples dissolved in methanol were hydrogenated by bubbling $\mathrm{H}_{2}$ gas in a suspension of platinum oxide $(10 \mathrm{mg} / \mathrm{ml})$. The hydrogenated and non-hydrogenated methyl esters of the samples were converted to their trimethylsilyl (TMS) ether derivatives with the mixture of $N$-trimethylsilyl imidasole/ $N, O$-bis-trimethylsilyl trifluoroacetamide $(2: 1, \mathrm{v} / \mathrm{v})$ for 2 $\mathrm{h}$ at room temperature. The samples were also converted to the tert-butyldimethylsilyl (tBDMS) ether derivatives as described by Woollard and Mallet. ${ }^{23)}$ Electron impact mass analysis of methyl ester-TMS ether derivatives of the samples was performed with a Shimadzu GC-MS $9100 \mathrm{MK}$. The electron energy was $70 \mathrm{eV}$ in all cases. The GC column for the Shimadzu GC-MS $9100 \mathrm{MK}$ consisted of a 15 $\mathrm{m} \times 0.515 \mathrm{~mm}$ DB-17 megabore capillary column $(1 \mu \mathrm{m}$ thickness, J \& W Scientific, Folson, CA) and was first kept at $150^{\circ} \mathrm{C}$ for 1 min after injection, then raised to $250^{\circ} \mathrm{C}$ at $6^{\circ} \mathrm{C} / \mathrm{min}$. The temperatures of the injector, separator and ion source were maintained at $250^{\circ} \mathrm{C}$, and the $\mathrm{He}$ carrier gas flow was set at $15 \mathrm{ml} / \mathrm{min}$.

In order to determine the number of double bonds of methyl ester-TMS or -tBDMS ether derivatives of the samples, GC-MS analysis by a Shimadzu GCMS-QP1000A was performed on a $1.1 \mathrm{~m} \times 3 \mathrm{~mm}$ column of $2 \% \mathrm{OV}-17$ on Chromosorb W (80-100 mesh) under isothermal conditions at $220^{\circ} \mathrm{C}$. Injector, separator and ion source temperatures were kept at $230^{\circ} \mathrm{C}$, and the $\mathrm{He}$ carrier gas flow was 
set at $30 \mathrm{ml} / \mathrm{min}$.

\section{Results}

\section{Identification of $A A$ Metabolites}

When the microsome or cytosol fraction prepared from red sea bream gill was incubated with $\left[1-{ }^{14} \mathrm{C}\right] \mathrm{AA}$, a
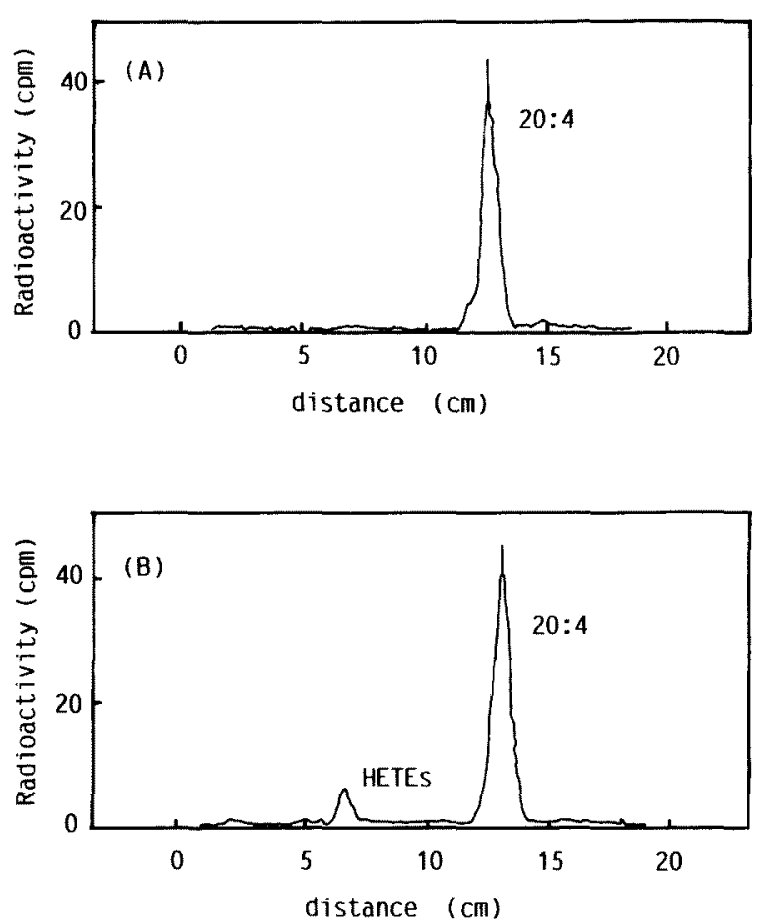

Fig. 1. Thin-layer radiochromatograms of the reaction products from AA.

$\left[1{ }^{14} \mathrm{C}\right] \mathrm{AA}\left(0.75 \mathrm{nmol}, 5 \times 10^{4} \mathrm{dpm}\right)$ was incubated with the cytosol (A) or microsome fraction (B) of red sea bream gill. Reactions were carried out at $17^{\circ} \mathrm{C}$ for $30 \mathrm{~min}$, and extraction and TLC were performed as described in Materials and Methods. radioactive peak corresponding to authentic HETEs was observed only in the ethereal extract obtained from the microsome fraction, and the conversion rate of $\mathrm{AA}$ to HETEs was approximately $9 \%$ (Fig. 1-B). In contrast, no detectable conversion to radioactive product occurred in the cytosol fraction (Fig. 1-A). The monohydroxy fraction was obtained by silicic acid column chromatography from the ethereal extract of the microsome fraction, and subjected to reverse-phase HPLC (Fig. 2). Four radioactive peaks were detectable. Peaks I and II, which were co-chromatographed with authentic 8- and 12-HETEs and 15 HETE, respectively, were collected and subjected to straight-phase HPLC (Figs. 3-A and 3-B). Radioactive

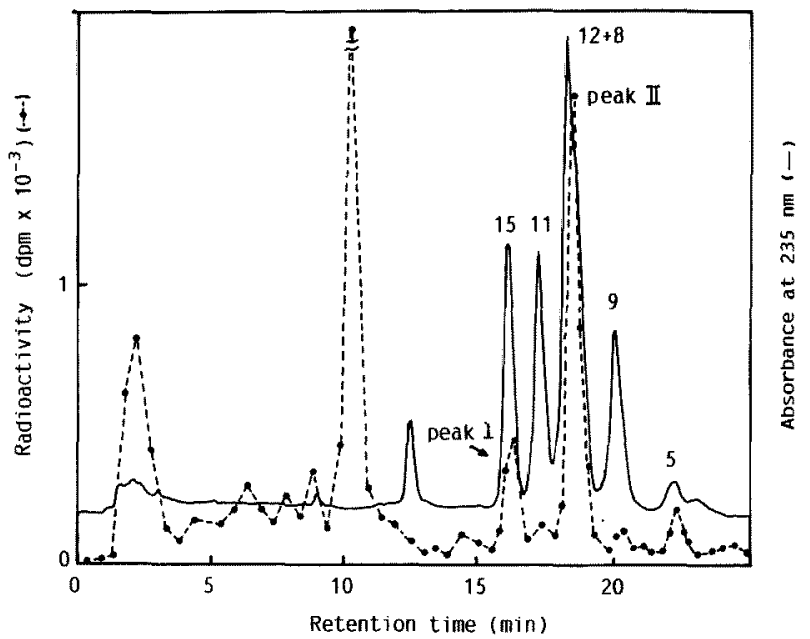

Fig. 2. Reverse-phase HPLC chromatogram of the reaction products from AA.

The ethereal extract obtained from the incubation of $\left[1-{ }^{14} \mathrm{C}\right] \mathrm{AA}$ with the microsome fraction of red sea bream gill was purified by silicic acid chromatography and subjected to reverse-phase HPLC as described under Materials and Methods. Elution of authentic HETE standards is indicated by numbers; 5-HETE (5), 8-HETE (8), 9HETE (9); 11-HETE (11), 12-HETE (12) and 15-HETE (15).
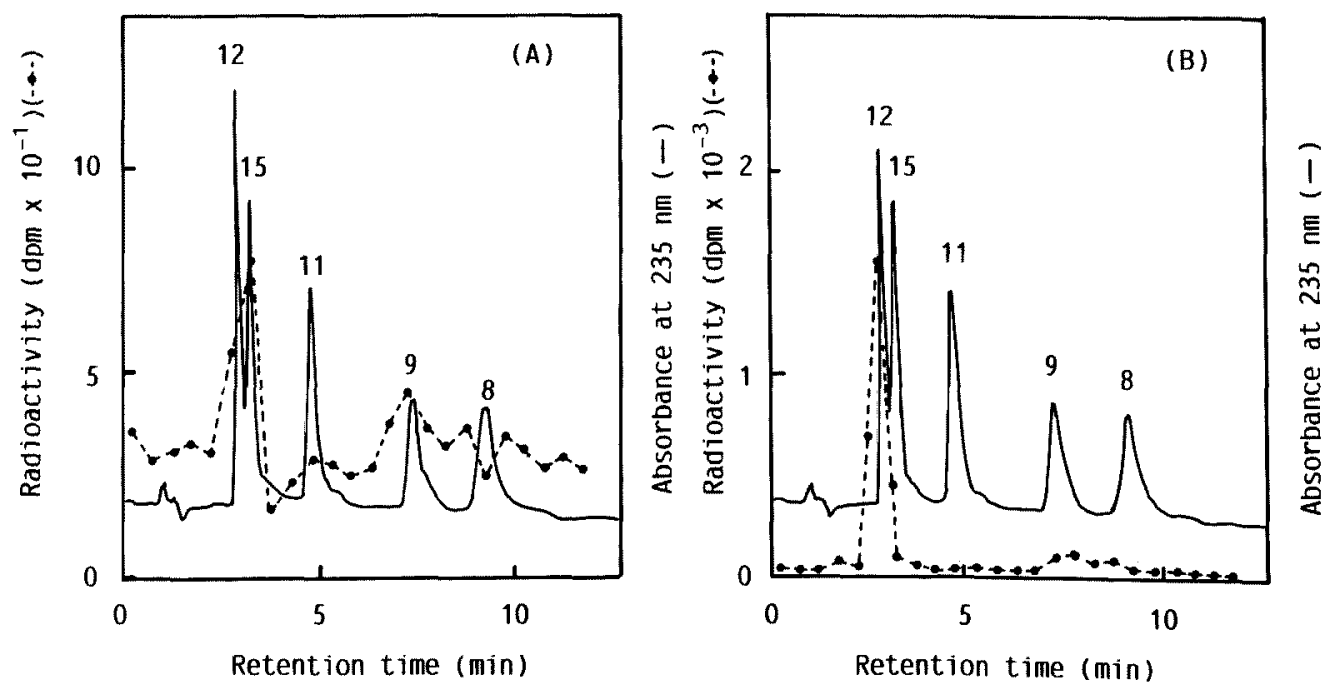

Fig. 3. Straight-phase HPLC chromatograms of the reaction products from AA.

Radioactive peaks I (A) and II (B) separated by reverse-phase HPLC, as shown in Fig. 2, were collected separately and subjected to straightphase HPLC as described under Materials and Methods. Elution of authentic HETE standards is indicated as shown in Fig. 2. 
peaks I and II coincided with authentic 15-HETE and 12HETE in retention times, respectively. It was shown that AA was mainly converted to 12-HETE and also 15-HETE in the microsome fraction from red sea bream gill.

\section{Identification of the Endogeneous Products}

Ethereal extract obtained from the microsome fraction of red sea bream gill was subjected to silicic acid column chromatography, and the obtained monohydroxy fraction was analyzed by reverse-phase HPLC. Two main peaks absorbing at $235 \mathrm{~nm}$ were observed in Fig. 4-A, where peak 2 was coeluted with authentic 12-HETE by reverse-phase HPLC. Peaks 1 and 2 were collected and then separated by straight-phase HPLC. Peak 1 was purified as a single component denoted as peak 1 in Fig. 4-B. Peak 2 was separated into two components as peak 2-1 and peak 2-2 in Fig. 4-C, where peak 2-1 coincided with authentic 12-HETE. The ultraviolet spectra of peaks 1, 2-1 and 2-2 showed maximum absorption at around $235 \mathrm{~nm}$ (Fig. 5), suggesting the presence of a conjugated diene in the compound. Peaks 1, 2-1 and 2-2 were converted into the methyl esterTMS ether derivatives and analyzed. Characteristic ions of a methyl ester and TMS ether derivative of peak 2-1 were observed at m/z $406[\mathrm{M}], 391\left[\mathrm{M}-\mathrm{CH}_{3}\right]^{+}, 375\left[\mathrm{M}-\mathrm{OCH}_{3}\right]^{+}$, $316\left[\mathrm{M}-\mathrm{HOSi}\left(\mathrm{CH}_{3}\right)_{3}\right]^{+}$, and 295 (Fig. 6). This spectrum was identical to that of authentic 12L-hydroxy-5,8,10,14eicosatetraenoic acid. The absolute configuration of the 12-hydroxyl group of peak 2-1 was not determined. The mass spectra of methyl ester-TMS and methyl estertBDMS ether derivatives before and after hydrogenation of peak 2-1 were essentially identical to those of $12-$ HETE $^{23)}$ (data not shown). The compound denoted as peak 2-1 was thus identified as 12-HETE.

A methyl ester-TMS ether derivative of peak 1 exhibited the following ions upon mass spectrometry: $\mathrm{m} / \mathrm{z} 404[\mathrm{M}]$, $389\left[\mathrm{M}-\mathrm{CH}_{3}\right]^{+}, 373\left[\mathrm{M}-\mathrm{OCH}_{3}\right]^{+}, 314\left[\mathrm{M}-\mathrm{HOSi}\left(\mathrm{CH}_{3}\right)_{3}\right]^{+}$ and 295 (Fig. 7). This spectrum was identical to that reported for 12-HEPE. ${ }^{5,24}$ In addition, the mass spectra of methyl ester-TMS or -tBDMS ether derivatives of peak 1 before and after hydrogenation also supported that the compound peak 1 correspond to 12-HEPE (data not shown).

A methyl ester-TMS ether derivative of peak 2-2 exhibited mass spectrometric peaks of the following ions: $\mathrm{m} / \mathrm{z}$ $430[\mathrm{M}], 415\left[\mathrm{M}-\mathrm{CH}_{3}\right]^{+}, 340\left[\mathrm{M}-\mathrm{HOSi}\left(\mathrm{CH}_{3}\right)_{3}\right]^{+}$and 321 (Fig. 8). This pattern was identical to that of 14-hydroxydocosahexaenoic acid (14-HDHE). ${ }^{5,25)}$ The methyl esterTMS or -tBDMS ether derivative of peak 2-2 and their hydrogenated derivatives were then analyzed by a Shimadzu GCMS-QP1000A. The methyl ester-TMS ether derivative of peak 2-2 showed a single intense ion (base peak) at $\mathrm{m} / \mathrm{z} 321$ (data not shown). After the hydrogenation, however, two intense ions were found at $\mathrm{m} / \mathrm{z} 215$ and 329 in the mass spectrum (data not shown). The mass spectra of the tBDMS ether derivatives of peak 2-2 before and after hydrogenation were essentially identical to those of 14-HDHE. ${ }^{5}$ Accordingly, the compound peak 2-2 was identified as 14-HDHE.

\section{Discussion}

The present study showed that there are catalytic oxida-
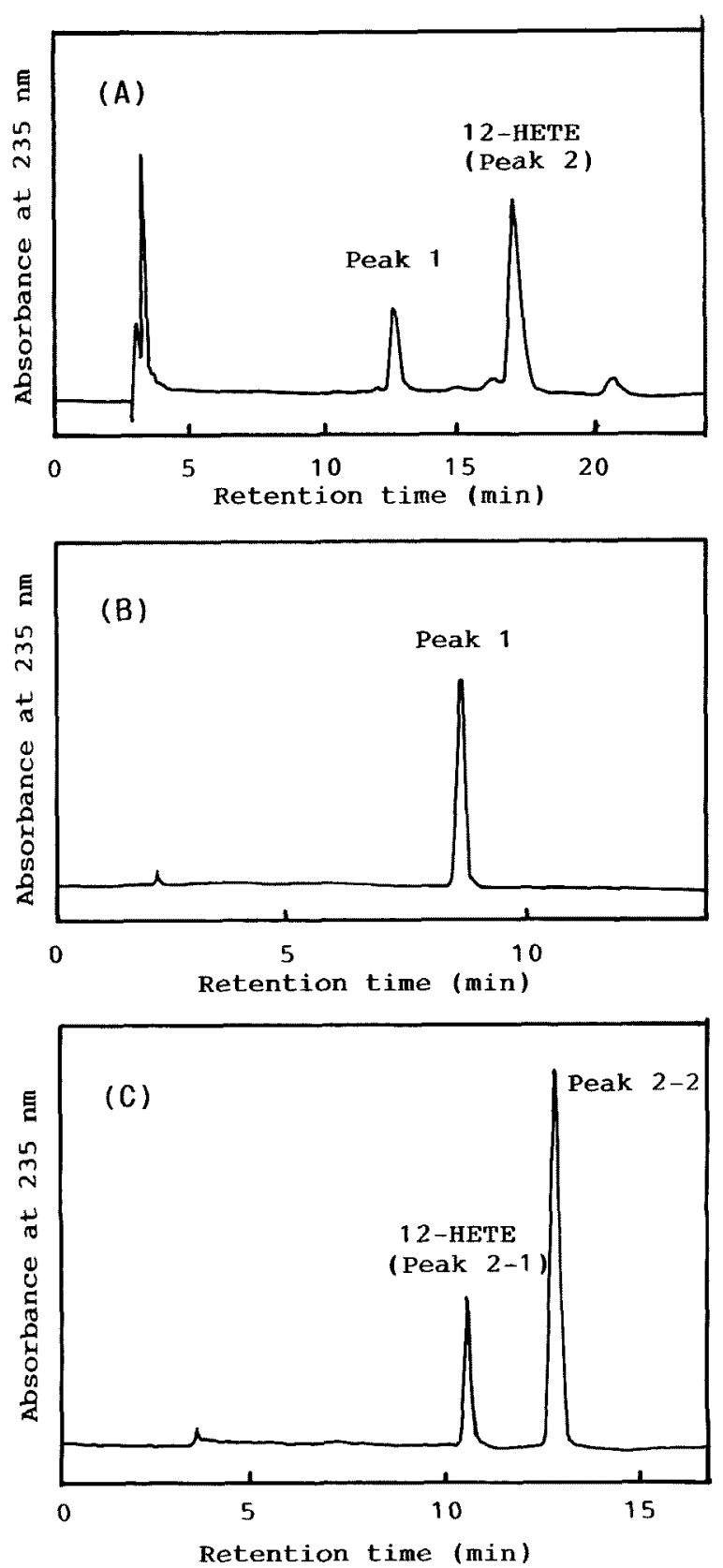

Fig. 4. HPLC chromatograms of the endogenous products in the microsome fraction of red sea bream gill.

Following extraction and silicic acid chromatography, samples were subjected to reverse-phase HPLC (A), and obtained peaks I and 2 were further separated into peak 1 (B) and peaks 2-1 and 2-2 (C), respectively, by straight-phase HPLC as described under Materials and Methods.

tion processes of exogeneous AA to 12-HETE and 15HETE. In addition, AA, EPA and DHA are endogeneously converted to 12-HETE, 12-HEPE and 14-HDHE, respectively, in the microsomes of red sea bream gill. Since 12-lipoxygenase acts on the $\mathrm{n}-\mathbf{9}$ position in the fatty acid molecule, a hydroperoxyl group is respectively introduced at the 12,12 and 14 position of AA, EPA and DHA, and the hydroperoxides were converted to their monohydroxy derivatives, as revealed in the present analysis. In mam- 

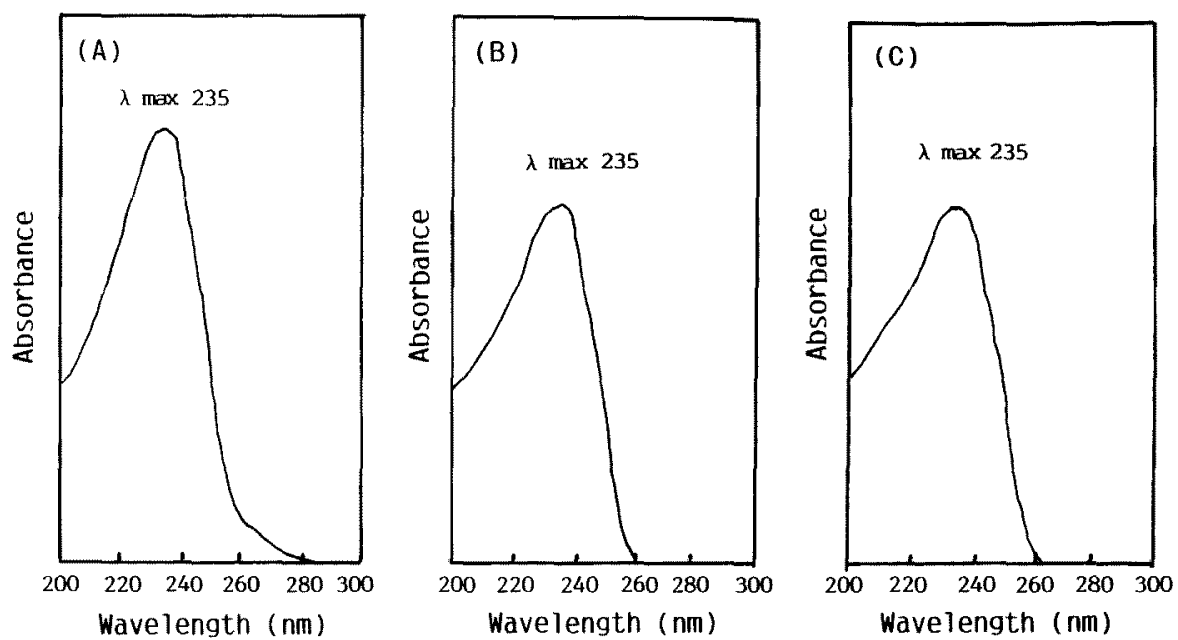

Fig. 5. Ultraviolet absorption spectra of the compounds obtained after straight-phase HPLC.

All spectra of the compounds denoted as peak 1 (A), peak 2-1 (B) and peak 2-2 (C) were recorded with methanol.

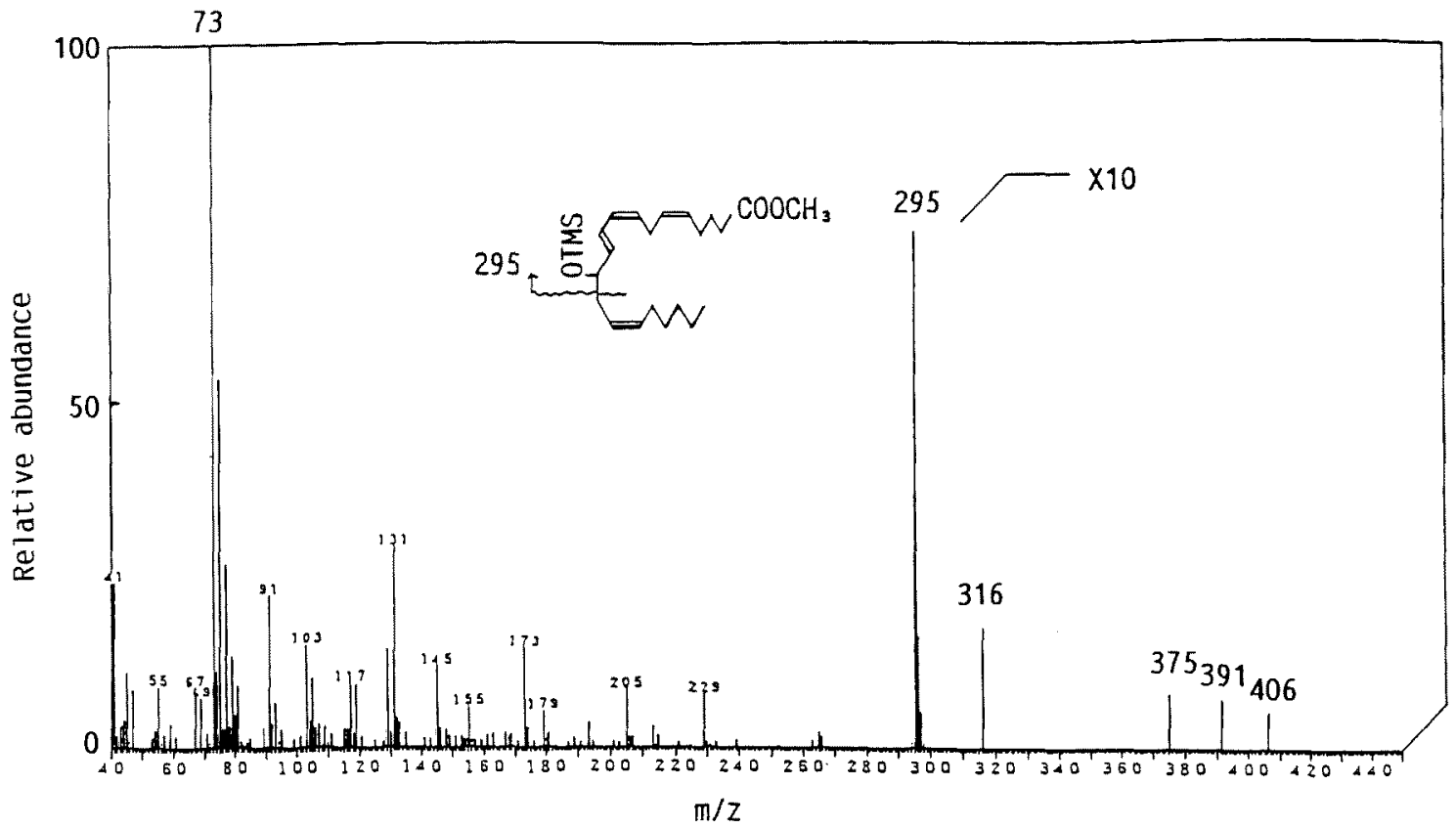

Fig. 6. Mass spectrum of the methyl ester TMS ether derivative of the compound (peak 2-1). Sample was subjected to a Shimadzu GC-MS 9100 MK.

malian tissues and cells, 12-lipoxygenase enzymes are generally distributed in the cytosol fraction. ${ }^{1)}$ In trout gill too, 12-lipoxygenase was found in the cytosol fraction.") Capdevila et al. ${ }^{26}$ observed that rat microsomal cytochrome P-450 catalyzes the oxidation of AA(n-6) to 9-, $11-, 12-$, and 15-HETEs in the presence of NADPH. However, the conversion of exogenous AA to 12-HETE in the red sea bream gill microsomes is not stimulated by the addition of NADPH (data not shown). Although the effect of lipoxygenase inhibitors on the production of the above oxgenated derivative has not been confirmed, the authors assumed from the above data that 12-HETE, 12-HEPE and 14-HDHE were produced by the action of 12-lipoxygenase in the microsomes of red sea bream gill stored for
1 to 3 months at $-40^{\circ} \mathrm{C}$. We already found that AA, EPA and DHA were oxidized more rapidly in the cytosol fraction than in the microsome fraction of red sea bream gill by measuring the rate of oxygen absorption with polarographic analysis (data not shown). However, this was not found in the conversion of AA to monohydroxy derivatives in the cytosol fraction of red sea bream gill which had been stored for $1-3$ months at $-40^{\circ} \mathrm{C}$ (Fig. 1-A). Therefore, it was assumed that lipoxygenase-like enzymes existed in both microsome and cytosol fractions in red sea bream gill and that the enzyme in the cytosol fraction was denatured during the frozen storage. However, further study is needed on the lipoxygenase-like activity of cytosol fraction. 


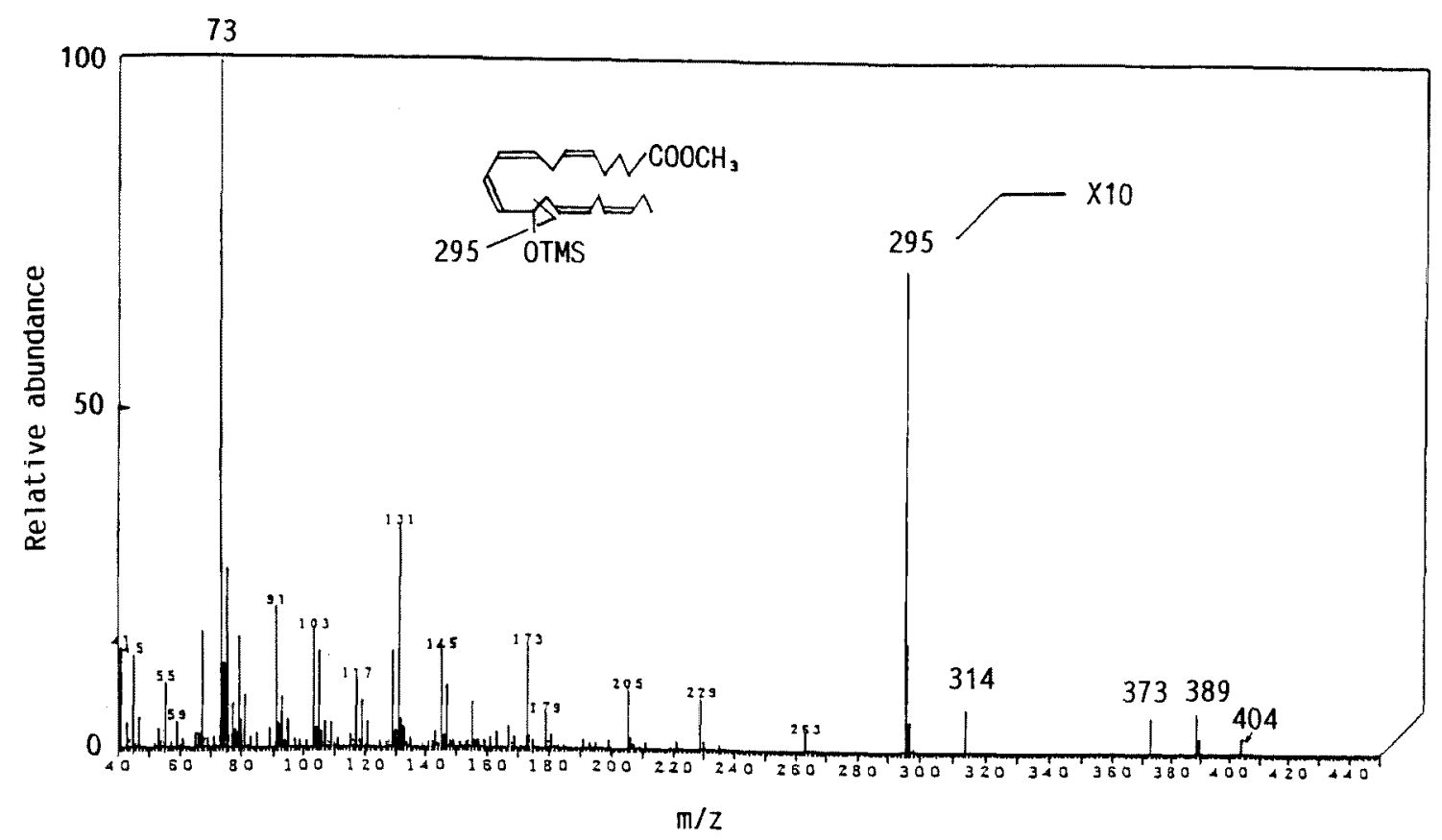

Fig. 7. Mass spectrum of the methyl ester TMS ether derivative of the compound (peak 1). Sample was subjected to a Shimadzu GC-MS $9100 \mathrm{MK}$.

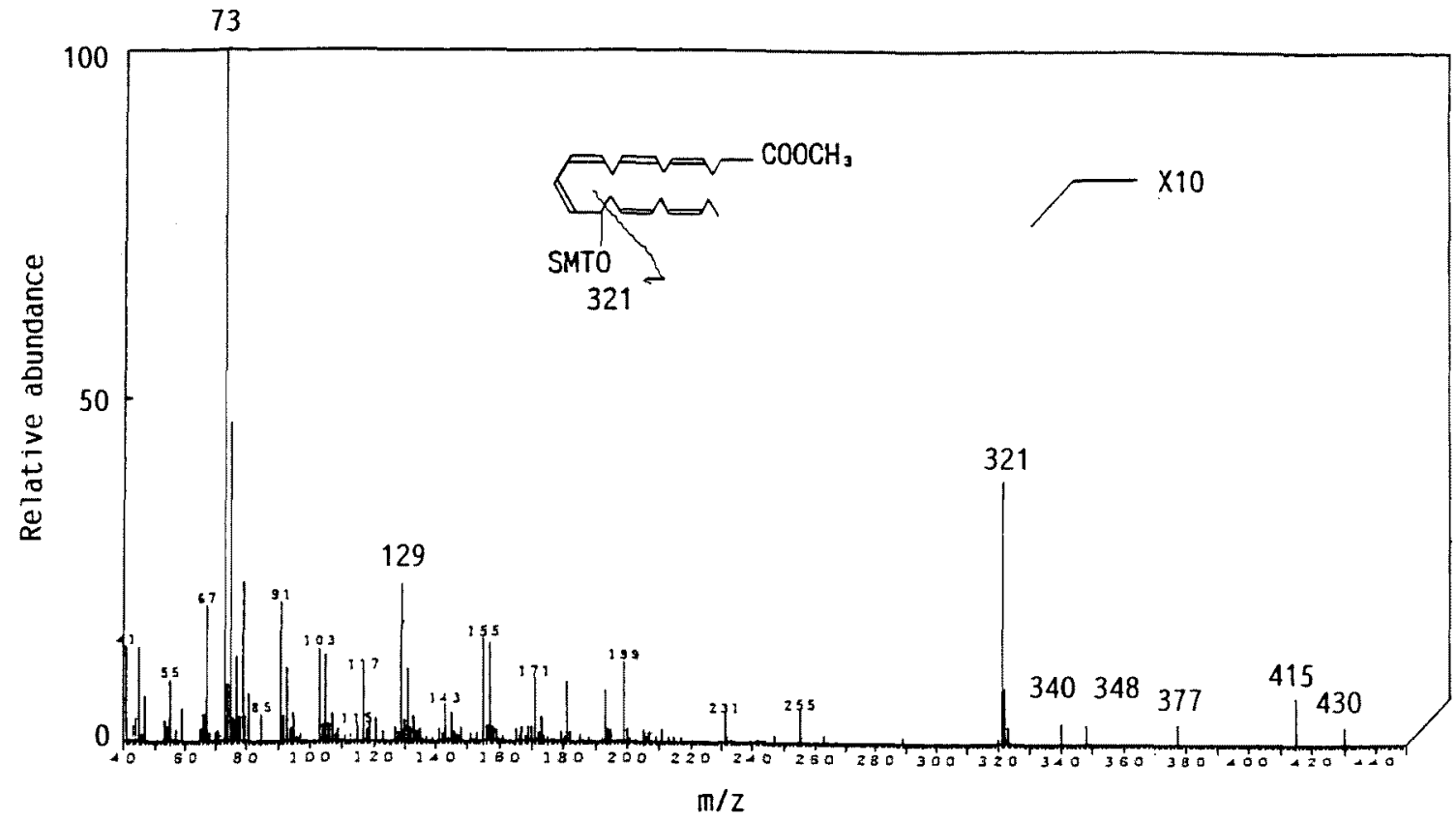

Fig. 8. Mass spectrum of the methyl ester TMS ether derivative of the compound (peak 2-2). Sample was subjected to Shimadzu GC-MS $9100 \mathrm{MK}$.

It remains to be elucidated whether a minor production of 15-HETE is attributed to the action of 15-lipoxygenase or 15-oxygenase activity of 12-lipoxygenase in the microsomes of red sea bream gill (Figs. 2 and 3). The rabbit reticulocyte 15-lipoxygenase converts AA to a mixture of 15-HPETE and 12-HPETE in a ratio of about 15:1. ${ }^{27)}$

In mammalian tissues or cells in which endogenous DHA content is low, the conversion of DHA to monohydroxy derivatives is too low compared with the HETEs production. ${ }^{25,28,29)}$ On the other hand, in canine retina containing more DHA than AA and EPA in phospholipids, conversion of DHA occurs as frequently as that from AA to lipoxygenase-reaction products in the bovine and rat retina. ${ }^{30)}$

The $\mathbf{n}-\mathbf{3}$ polyunsaturated fatty acids, EPA and DHA are the major fatty acid constituents in fish tissue phospholipids. ${ }^{3)}$ In rainbow trout gill whose DHA is rich in phospholipids, AA and DHA are almost equally convert- 
ed to their monohydroxylated derivatives, suggesting a 12lipoxygenase. ${ }^{5)}$ According to the area ratio of the absorbance of $235 \mathrm{~nm}$ in peaks 1 and 2 (Fig. 4-A) and peaks 2-1 and 2-2 (Fig. 4-C), the authors calculated that the ratio of endogenous production of 12-HETE, 12-HEPE and 14HDHE is approximately $1: 1.8: 3.7$. Similarly, the ratio of AA(n-6), EPA (n-3) and DHA(n-3) in the phospholipids of the gill tissues of red sea bream was approximately 1:1.4:3.6 (data not shown), which is very close to the above value of the production ratio of monohydroxy derivatives from AA, EPA and DHA. Therefore, it may be inferred that the production of 12-HETE, 12-HEPE and 14-HDHE is dependent on their substrate concentration in membrane phospholipids. Claeys et al ${ }^{31)}$ pointed out that the higher substrate preference of porcine leucocyte 12-lipoxygenase on linoleic acid compared to AA is relevant to higher concentrations of linoleic acid than AA in phospholipids. Yokoyama et al. ${ }^{32)}$ also confirmed that the preferred substrates depend on the substrate concentration: At a higher substrate concentration $(100 \mu \mathrm{M})$, porcine leucocyte enzyme reacts more actively to linoleic acid than AA.

HETEs are subsequently converted to other metabolic products such as diHETE and triHETEs in mammalian cells and tissues. ${ }^{1)}$ In rainbow trout gill, AA can be converted to $8,11,12$ - and $10,11,12$-trihydroxy derivatives via the initial reactions of lipoxygenase. ${ }^{6}$ It is likely that the metabolite eluted at $10 \mathrm{~min}$ is dihydroxy or trihydroxy derivative of AA (Fig. 2); however, this remains to be clarified. Further study is needed on these metabolites.

Acknowledgments This work was supported in part by a Grant-in-Aid for Scientific Research from the Ministry of Education, Science, and Culture of Japan (No. 01480082) and by grants from the Fisheries Agency of the Ministry of Agriculture, Forestry and Fisheries of Japan. We wish to express our sincere thanks to Professor Dr. Shozo Yamamoto and Dr. Natsuo Ueda, Department of Biochemistry, Tokushima University School of Medicine for their technical guidance on accomplishing the present experiment.

\section{References}

1) A. A. Spector, J. A. Gordon, and S. A. Moore: Hydroxyeicosatetraenoic acids (HETEs). Prog. Lipid Res. , 27, 271-323 (1988).

2) B. L. Sloomiany, L. N. Murty, Y. H. Liau, and A. Slomiany: Lipid metabolism in fish. Prog. Lipid Res., 26, 53-85 (1987).

3) R. J. Henderson and D. R. Tocher: The lipid composition and biochemistry of freshwater fish. Prog. Lipid Res., 26, 281-347 (1987).

4) J. B. German, G. Bruckner, and J. E. Kinsella: Evidence against a $\mathrm{PGF}_{4}$ prostaglandin structure in trout tissuea correction. Prostaglandins, 26, 207-210 (1983).

5) J. B. German, G. G. Bruckner, and J. E. Kinsella: Lipoxygenase in trout gill tissue acting on arachidonic acid, eicosapentaenoic acid and docosahexaenoic acids. Biochim. Biophys. Acta, 875, 12-20 (1986).

6) J. B. German and J. E. Kinsella: Hydroperoxide metabolism in trout gill tissue: effect of glutathione on lipoxygenase products generated from arachidonic acid and docosahexaenoic acid. Biochim. Biophys. Acta, 877, 290-298 (1986).

7) J. B. German and J. E. Kinsella: Hydroperoxide metabolism in trout gill tissue: effect of glutathione on lipoxygenase products generated from arachidonic acid and docosahexaenoic acid. Biochim. Biophys. Acta, 879, 378-387 (1986).

8) J. B. German and R. Berger: Formation of 8,15-dihydroxy eicosapentaenoic acid via 15- and 12-lipoxygenase in fish gill. Lipids,
$25,849-853$ (1990).

9) J. B. German and M.-L Hu: Oxidant stress inhibits the endogeneous production of lipoxygenase metabolites in rat lungs and fish gills. Free Radical biol. Med., 8, 441-448 (1990).

10) M. Winkler, G. Pilhofer, and J. B. German: Stereochemical specificity of the n-9 lipoxygenase of fish gill. J. Food Biochem., 15, 437-448 (1991).

11) J. B. German and J. E. Kinsella: Lipid oxidation in fish tissue. Enzymatic initiation via lipoxygenase. J. Agric. Food Chem., 33, 680683 (1985).

12) R. J. Hsieh, J. B. German, and J. B. Kinsella: Lipoxygenase in fish tisue: some properties of the 12-lipoxygenase from trout gill. $J$. Agric. Food Chem., 36, 680-685 (1988).

13) R. J. Hsieh, J. B. German, and J. E. Kinsella: Relative inhibitory potencies of flavonoids on 12-lipoxygenase of fish gill. Lipids, 23, 322-326 (1988).

14) C.-H. Zhang, T. Shirai, T. Suzuki, and T. Hirano: Lipoxygenaselike activity and formation of characteristic aroma compounds from wild and cultured ayu. Nippon Suisan Cakkaishi, 58, 959-964 (1992).

15) T. R. Pettitt, A. F. Rowley, and S. E. Barrow: Synthesis of leukotriene $B$ and other conjugated triene lipoxygenase products by blood cells of rainbow trout, salmo gairdneri. Biochim. Biophys. Acta, 1003, 1-8 (1989).

16) T. R. Pettitt and A. F. Rowley: Uptake, incorporation and calciumionophore-stimulated mobilization of arachidonic, eicosapentaenoic and docosahexaenoic acids by leucocytes of the rainbow trout, Salmo gairdneri. Biochim. Biophys. Acta, 1042, 62-69(1990).

17) D. Piomelli: Leukotrienes in teleost fish gills. Naturwissenschaften, 72, 276-277 (1985).

18) D. R. Tocher and J. R. Sargent: The effect of calcium ionophore A23187 on the metabolism of arachidonic acid and eicosapentaenoic acid in neutrophils from a marine teleost fish rich in (n-3) polyunsaturated fatty acids. Comp. Biochem. Physiol., 87B, 733739 (1987).

19) M. Kayama, T. Sado, N. Iijima, T. Asada, M. Igarashi, T. Shiba, R.Yamaguchi, and T. Hirai: The prostaglandin synthesis in carp thrombocytes. Nippon Suisan Gakkaishi, 51, 1911 (1985).

20) M. Kayama, T. Sado, and N. Iijima: The prostaglandin synthesis in rainbow trout thrombocyte. Nippon Suisan Gakkaishi, 52, 925 (1986).

21) M. Kayama, H. Matsumoto, T. Hada, J. Hirano, and T. Funada: Comparison of aggregation behaviors in human and fish blood. Nip. pon Suisan Gakkaishi, 55, 697-701 (1989).

22) H. Matsumoto, N. Iijima, and M. Kayama: The prostaglandin synthesis in marine fish thrombocyte. Comp. Biochem. Physiol., 93B, 397-402 (1989).

23) P. M. Woollard and A. I. Mallet: Lipoxygenase products. A novel gas chromatographic-mass spectrophotometric assay for monohydroxy fatty acids. J. Chromatogra., 306, 1-21 (1984).

24) S. M. Taylor, W. W. Laegreid, J. R. Heidel, K. M. Straub, H. D. Liggitt, R. M. Silflow, R. G. Breeze, and R. W. Leid: Arachidonic and eicosapentaenoic acid metabolism in bovine neutrophils and platelets: Effect of calcium ionophore. J. Leukocyte Biol., 42, 253262 (1987).

25) M. I. Averdano and H. Sprecher: Synthesis of hydroxy fatty acids from $4,7,10,13,16,19-\left[1-{ }^{14} \mathrm{C}\right]$ docosahexaenoic acid by human platelets. J. Biol. Chem., 258, 9339-9343 (1983).

26) J. Capdevila, L. J. Marnett, N. Chacos, R. A. Prough, and R. W. Estabrook: Cytochrome P-450-dependent oxygenation of arachidonic acid to hydroxyeicosatetraenoic acids. Proc. Natl. Acad. Sci. USA, 79, 767-770 (1982).

27) R. W. Bryant, T. Schewe, S. M. Rapoport, and J. M. Bailey: Leukotriene formation by purified reticulocyte lipoxygenase enzyme. $J$. Biol. Chem., 260, 3548-3555 (1985).

28) E. J. Corey, C. Shih, and J. R. Cashman: Docosahexaenoic acid is a strong inhibitor of prostaglandin but not leukotriene biosynthesis. Proc. Natl. Acad. Sci. USA, 80, 3581-3584 (1983).

29) S. Fisher, C. V. Schacky, W. Siess, T. Strasser, and P. C. Weder: Uptake, release and metabolism of docosahexaenoic acid (DHA C22:6 $(3)$ in human platelets and neutrophils. Biochem. Biophys. 
Res. Commun., 120, 907-918 (1984).

30) N. G. Bazan, D. L. Birkle, and T. Sanjeeva Reddy: Docosahexaenoic acid $(22: 6, n-3)$ is metabolized to lipoxygenase reaction products in the retina. Biochem. Biophys. Res. Commun., 125, 741-747 (1984).

31) M. Claeys, G. A. A. Kivits, E. Christ-Hazelhof, and D. H. Nugteren: Metabolic profile of linoleic acid in porcine leukocytes through the lipoxygenase pathway. Biochim. Biophys. Acta, 837, 35-51 (1985).

32) C. Yokoyama, F. Shinjo, T. Yoshimoto, S. Yamamoto, J. A. Oates, and A. R. Brash: Arachidonate 12-lipoxygenase purified from porcine leukocytes by immunoaffinity chromatography and its reactivity with hydroperoxyeicosatetraenoic acids. J. Biol. Chem., 261, 16714-16721 (1986). 